\title{
Synthesis of Novel Nanostructured Composite Cathode Materials for Lithium-Ion Batteries Using Mechanical Activation
}

\author{
N.V. Kosova ${ }^{1,2}$ and E.T. Devyatkina ${ }^{1}$ \\ ${ }^{I}$ Institute of Solid State Chemistry and Mechanochemistry, Siberian Branch, Russian Academy of \\ Sciences, ul. Kutateladze 18, Novosibirsk, 630128 Russia \\ ${ }^{2}$ Novosibirsk State University, ul. Pirogova 2, Novosibirsk, 630090 Russia \\ e-mail: kosova@solid.nsc.ru
}

Presented by Academician V.V. Boldyrev April 21, 2014

The recent launching of production of hybrid and electric vehicles made great demands on lithium-ion batteries (LIBs). One of the promising approaches to the optimization of their properties is in the development of new blended composite electrode materials consisting of two (or more) active components in order to use the advantages of the both of them [1]. Due to a unique combination of properties, the mixed materials show some advantages over the individual components. This includes the longer lifetime, the decreased capacity fading upon the cycling, lower price, the improved thermal stability, more acceptable profiles of charge-discharge curves and operating voltage, etc. For instance, the cathode materials with a layered structure $\left(\mathrm{LiCoO}_{2}\right)$ have a high Coulomb capacity and good electrochemical properties, but are expensive and thermally unstable. On the contrary, cathode materials with a spinel structure $\left(\mathrm{LiMn}_{2} \mathrm{O}_{4}\right)$ are characterized by high thermal stability and good cycleability, but show lower capacity. Mixing these two cathode materials minimizes their disadvantages, and the composite material is characterized by high energy or power, along with higher stability and lower price.

In the present work, we formulate the new approaches to the development of novel composite electrode materials for LIB, using the mechanical activation method (MA). MA with high-energy mechanoactivators is a modern energy- and eco-efficient method of fine grinding, mixing, and activation of solid reagents and is widely used to prepare different functional materials $[2,3]$. As an example, we report the results of studying the synthesis, structure, morphology, and electrochemical properties of the composite cathode materials prepared by different procedures: 1) joint MA of two individual cathode materials (the $\mathrm{LiCoO}_{2} / \mathrm{LiMn}_{2} \mathrm{O}_{4}$ composites); 2) direct mechanochemically assisted solid state synthesis starting from a multicomponent mixture of reagents $\left(\mathrm{LiFePO}_{4} / \mathrm{Li}_{3} \mathrm{~V}_{2}\left(\mathrm{PO}_{4}\right)_{3}\right.$ composites); 3) synthesis via heatinduced partial decomposition of a single-phase nanosized cathode material, prepared by MA, 
with the elimination of a gaseous by-product and the formation of the second electrochemically active component (the $\mathrm{LiVPO}_{4} \mathrm{~F} / \mathrm{Li}_{3} \mathrm{~V}_{2}\left(\mathrm{PO}_{4}\right)_{3}$ composites).

Mechanical activation was performed using an AGO-2 planetary mill. The annealing of the activated mixtures was carried out at $200-400{ }^{\circ} \mathrm{C}$ in air to remove the gases absorbed during MA $\left(\mathrm{LiCoO}_{2} / \mathrm{LiMn}_{2} \mathrm{O}_{4}\right)$ or at $700-800{ }^{\circ} \mathrm{C}$ to complete the formation of the final product $\left(\mathrm{LiFePO}_{4} / \mathrm{Li}_{3} \mathrm{~V}_{2}\left(\mathrm{PO}_{4}\right)_{3} ; \mathrm{LiVPO}_{4} \mathrm{~F} / \mathrm{Li}_{3} \mathrm{~V}_{2}\left(\mathrm{PO}_{4}\right)_{3}\right)$. The as-prepared materials were analyzed by $\mathrm{X}$ ray powder diffraction method (XRD) using a Bruker D8 Advance diffractometer $(\mathrm{Cu} \mathrm{K \alpha}$ radiation; step $0.02 \mathrm{deg} / \mathrm{s}$ ); scanning electron microscopy on a LEO $1430 \mathrm{VP}$ scanning electron microscope, and galvanostatic cycling in half-cells with $\mathrm{Li}$ anode and an electrolyte based on a $1 \mathrm{M} \mathrm{LiPF}_{6}$ solution in a mixture of ethylene- and dimethyl carbonates. Phase transitions in the course of cycling were studied by in situ synchrotron diffraction at the high-resolution powder diffraction beamline P02.1 at PETRA III, DESY, using a PerkinElmer XRD 1621 detector. The lattice parameters were refined by the Rietveld method using the GSAS program package.

\section{EXPERIMENTAL}

$\mathrm{LiCoO}_{2} / \mathrm{LiMn}_{2} \mathrm{O}_{4}$ Composites

Layered lithium cobalt oxide $\mathrm{LiCoO}_{2}$ (space group $R-3 m$ ) [4] and lithium manganese spinel $\mathrm{LiMn}_{2} \mathrm{O}_{4}$ (space group $\mathrm{Fd} 3 \mathrm{~m}$ ) [5] are well known cathode materials for LIB. As compared to layered cathodes, $\mathrm{LiMn}_{2} \mathrm{O}_{4}$ is less expensive and less toxic and is characterized by higher operating voltage, better high-rate capability and thermal stability. Therefore, it is very attractive to be used as the second component in a mixture with $\mathrm{LiCoO}_{2}$. At the same time, $\mathrm{LiMn}_{2} \mathrm{O}_{4}$ has a lower Coulomb capacity and some disadvantages associated with the structural reconstruction upon the cycling and the Mn dissolution in the electrolyte, which can cause high capacity fading.

Earlier, it has been shown that some disadvantages of cathode materials can be overcome by the preparation of physical blends of these components in blenders [6-8]. In the present study, $\mathrm{LiCoO}_{2}$ and $\mathrm{LiMn}_{2} \mathrm{O}_{4}$ were jointly activated in a high-energy AGO-2 planetary mill. The X-ray powder diffraction patterns of the as-prepared products are a superposition of the reflections of the initial phases, $\mathrm{LiCoO}_{2}$ and $\mathrm{LiMn}_{2} \mathrm{O}_{4}$ (Fig. 1). The composites are characterized by an average particle size of about 100-200 nm and a good cycleability with a specific capacity of $\sim 110$ $\mathrm{mA} \cdot \mathrm{h} \cdot \mathrm{g}^{-1}[9,10]$. Lithium intercalation-deintercalation is accompanied by the $\mathrm{Co}^{3+} / \mathrm{Co}^{4+}$ and $\mathrm{Mn}^{3+} / \mathrm{Mn}^{4+}$ redox processes and the $\mathrm{LiCoO}_{2} \leftrightarrow \mathrm{CoO}_{2}$ and $\mathrm{LiMn}_{2} \mathrm{O}_{4} \leftrightarrow \mathrm{Mn}_{2} \mathrm{O}_{4}$ phase transitions. First, the $\mathrm{Co}^{3+} / \mathrm{Co}^{4+}$ pair is activated and then lithium deintercalation involves both couples.

$\mathrm{dQ} / \mathrm{dU}=\mathrm{f}(\mathrm{U})$ plot of the first cycle shows three redox peaks corresponding to the initial components: $\mathrm{LiCoO}_{2}$ and $\mathrm{LiMn}_{2} \mathrm{O}_{4}$. However, contrary to the similar physical blends (without MA), the redox peaks of $\mathrm{LiCoO}_{2}$ gradually vanish upon the following cycling of the composite. 
According to X-ray diffraction, the $\mathrm{LiCoO}_{2}$ phase is still preserved in the product after the $12^{\text {th }}$ cycle, although the intensity of its reflections in the X-ray powder pattern noticeably decreases and the $c$ parameter increases (Fig. 1). The decrease in the intensity of the $\mathrm{Co}^{3+} / \mathrm{Co}^{4+}$ peaks on the $d Q / d U=f(U)$ plots is most likely associated with a gradual transition of the layered to spinel structure in the composite.

\section{$\mathrm{LiFePO}_{4} / \mathrm{Li}_{3} \mathrm{~V}_{2}\left(\mathrm{PO}_{4}\right)_{3}$ Composites}

Orthorhombic lithium iron phosphate $\mathrm{LiFePO}_{4}$ (space group Pnmb) is a favorite among the framework-structured cathode materials due to its high operating voltage and electrochemical capacity, as well as the high structural, chemical and thermal stability [11]. However, it is characterized by the low electronic conductivity and lithium-ion diffusion. Lithium vanadium phosphate $\mathrm{Li}_{3} \mathrm{~V}_{2}\left(\mathrm{PO}_{4}\right)_{3}$ with a monoclinic structure (space group $P 2_{1} / n$ ) is a Nasicon-type compound with a high lithium-ion conductivity [12]. Earlier, it has been shown that, when charged to high potential $(4.8 \mathrm{~V})$, these cathodes undergo fast degradation [13].

In the present work, we prepared the $\mathrm{LiFePO} / \mathrm{Li}_{3} \mathrm{~V}_{2}\left(\mathrm{PO}_{4}\right)_{3}$ composites using MA by the joint carbothermal reduction of $\mathrm{Fe}_{2} \mathrm{O}_{3}$ and $\mathrm{V}_{2} \mathrm{O}_{5}$ in a mixture with $\mathrm{Li}_{2} \mathrm{CO}_{3}$ and $\left(\mathrm{NH}_{4}\right)_{2} \mathrm{HPO}_{4}$. Carbon, used as a reducing agent, hindered the sintering of the product particles, while its excess could be used to form an electronically conductive carbon coating. The X-ray powder diffraction pattern of the final product shows two sets of reflections due to $\mathrm{LiFePO}_{4}$ and $\mathrm{Li}_{3} \mathrm{~V}_{2}\left(\mathrm{PO}_{4}\right)_{3}$, which is evidence that the solid solutions do not form. The cycling curves have four plateaus corresponding to the following redox pairs: $\mathrm{Fe}^{2+} / \mathrm{Fe}^{3+}$ (below $3.4 \mathrm{~V}$ ) and $\mathrm{V}^{3+} / \mathrm{V}^{4+, 5+}$ (above 3.4 $\mathrm{V})$.

The mechanism of phase transitions upon charge and discharge of the composite was studied by in situ synchrotron diffraction. Figure 2 shows a set of diffraction patterns of the $\mathrm{LiFePO}_{4} / \mathrm{Li}_{3} \mathrm{~V}_{2}\left(\mathrm{PO}_{4}\right)_{3}$ composite upon its charge to $4.8 \mathrm{~V}$. It is seen that the process is accompanied by the consistent phase transitions: $\mathrm{LiFePO}_{4} \rightarrow \mathrm{FePO}_{4}$; $\mathrm{Li}_{3} \mathrm{~V}_{2}\left(\mathrm{PO}_{4}\right)_{3} \rightarrow \mathrm{Li}_{2.5} \mathrm{~V}_{2}\left(\mathrm{PO}_{4}\right)_{3} \rightarrow \mathrm{Li}_{2} \mathrm{~V}_{2}\left(\mathrm{PO}_{4}\right)_{3} \rightarrow \mathrm{LiV}_{2}\left(\mathrm{PO}_{4}\right)_{3} \rightarrow \mathrm{V}_{2}\left(\mathrm{PO}_{4}\right)_{3}$, characteristic of the individual components. Thus, fine mixing at the nanolevel does not change the potentials of the $\mathrm{Fe}^{2+} / \mathrm{Fe}^{3+}$ and $\mathrm{V}^{3+} / \mathrm{V}^{4+, 5+}$ redox couples, but facilitates better cycleabilty and higher rate capability of the composite as compared with individual components.

\section{$\mathrm{LiVPO}_{4} \mathrm{~F} / \mathrm{Li}_{3} \mathrm{~V}_{2}\left(\mathrm{PO}_{4}\right)_{3}$ Composites}

Lithium vanadium fluorophosphate $\mathrm{LiVPO}_{4} \mathrm{~F}$ with a triclinic structure (space group $P-1$ ) is a promising high-voltage cathode material [14]. However, the synthesis of $\mathrm{LiVPO}_{4} \mathrm{~F}$ is poorly reproducible. In the present work, $\mathrm{LiVPO}_{4} \mathrm{~F}$ was synthesized by annealing the activated mixture 
of $\mathrm{VPO}_{4}$ with $\mathrm{LiF}$. It has been established that when the duration or temperature of the treatment increase, $\mathrm{LiVPO}_{4} \mathrm{~F}$ partially decomposes with the elimination of gaseous $\mathrm{VF}_{3}$ and the formation of the $\mathrm{LiVPO}_{4} \mathrm{~F} / \mathrm{Li}_{3} \mathrm{~V}_{2}\left(\left(\mathrm{PO}_{4}\right)_{3}\right.$ composite with a nanodomain structure. It has been noticed that the discharge profile of the composite within the 3.0-4.8 $\mathrm{V}$ range has a declined form characteristic of a solid solution mechanism of $\mathrm{Li}$ intercalation-deintercalation instead of a plateau observed for the single-phase $\mathrm{LiVPO}_{4} \mathrm{~F}$ characteristic of a two-phase mechanism [15]. Figure 3 shows that the rate capability of the $\mathrm{LiVPO}_{4} \mathrm{~F} / \mathrm{Li}_{3} \mathrm{~V}_{2}\left(\left(\mathrm{PO}_{4}\right)_{3}\right.$ composite exceeds that of the single-phase $\mathrm{LiVPO}_{4} \mathrm{~F}$.

Thus, we proposed a facile and promising method of synthesis of nanostructured composite cathodes using MA which offers the possibility of development of novel electrode materials with more balanced characteristics as compared with individual components.

\section{ACKNOWLEDGEMENTS}

We are thankful to Dr. D.V. Novikov and Dr. H.-P. Liermann for their help in conducting the experiment at the high-resolution powder diffraction beamline P02.1 at Petra III, DESY, Helmholtz Association.

The work has been partially supported by the Russian Foundation for Basic Research (grant N 14-03-01082) and by the Ministry of Education and Science of the Russian Federation. The authors are thankful to D.V. Novikov and H.-P. Liermann for their support in the conducting the experiment at the station P02.1 of high resolution powder diffraction at PETRA III, DESY, Helmholtz Association. 


\section{FIGURE CAPTIONS}

Fig. 1. Rietveld-refined X-ray powder diffraction patterns of (1) the as-prepared $0.5 \mathrm{LiCoO}_{2} / 0.5 \mathrm{LiMn}_{2} \mathrm{O}_{4}$ composite and (2) the product formed upon its cycling (after the $12^{\text {th }}$ cycle). Inset shows the SEM image of the composite.

Fig. 2. A set of X-ray powder diffraction patterns obtained in the coarse of charging of the $0.75 \mathrm{LiFePO}_{4} / 0.25 \mathrm{Li}_{3} \mathrm{~V}_{2}\left(\mathrm{PO}_{4}\right)_{3}$ composite by in situ synchrotron diffraction. The synchrotron radiation wavelength is $\lambda=0.20727 \AA$.

Fig. 3. Specific discharge capacity vs. cycling rate $(\mathrm{C}, \mathrm{mA} / \mathrm{g})$ of (1) the $0.85 \mathrm{LiVPO}_{4} \mathrm{~F} / 0.15$ $\mathrm{Li}_{3} \mathrm{~V}_{2}\left(\mathrm{PO}_{4}\right)_{3}$ composite as compared with (2) the single-phase $\mathrm{LiVPO}_{4} \mathrm{~F}$. 


\section{REFERENCES}

1. Chikkannanavar, S.B., Bernardi, D.M., and Liu, L., J. Power Sources, 2014, vol. 248, pp. 91-100.

2. Boldyrev, V.V., Usp. Khim., 2006, vol. 75, no. 3. pp. 203-216.

3. Avvakumov, E., Senna, M., and Kosova, N. Soft Mechanochemical Synthesis: A Basis for New Chemical Technologies, Boston, Dordrecht, London: Kluwer, 2001.

4. Mizushima, K., Jones, P.C., Wiseman, P.J., and Goodenough, J.B., Mater. Res. Bull., 1980, vol. 15, pp. 783-789.

5. Thackeray, M.M., Johnson, P.J., de Picciotto, L.A., Bruce, P.G., and Goodenough, J.B., Mater. Res. Bull., 1984, vol. 19, pp. 179-187.

6. Numata, T., Amemiya, C., Kumeuchi, T., Shirakata, M., and Yonezawa, M., J. Power Sources, 2001, vol. 97-98, pp. 358-360.

7. Ma, Z.F., Yang, X.Q., Liao, X.Z., Sun, X., and McBreen, J., Electrochemistry Commun., 2001, vol. 3, no. 8, pp. 425-428.

8. Albertus, P., Christensen, J., and Newman, J., J. Electrichem. Soc., 2009, vol. 156, no 7, pp. A606-A618.

9. Kosova, N.V., Devyatkina, E.T., Kaichev, V.V., and Slobodyuk, A.B., Solid State Ionics, 2011, vol. 192, pp. 284-288.

10. Kosova, N.V. and Devyatkina, E.T., Elektrochimiya, 2012, vol.48, no. 2, pp. 351-361.

11. Padhi, A.K., Nanjundaswamy, K.S., and Goodenough, J.B., J. Electrochem. Soc., 1997, vol. 144, no. 4, pp. 1188-1194.

12. Huang, H., Yin, S.C., Kerr, T., Taylor, N., and Nazar, L.F., Adv. Mater., 2002, vol. 14 , no. 21 , pp. 1525-1528.

13. Wang, L., Li, Z., Xu, H., and Zhang, K., J. Phys. Chem. C, 2008, vol. 112, pp.308-312.

14. Barker, J., Saidi, M.Y., and Swoyer, J.L., J. Electrochem. Soc., 2003, vol. 150, pp. A1394-A1398. 
15. Kosova, N.V., Devyatkina, E.T., Slobodyuk, A.B., and Gutakovskii, A.K., J. Solid State Electrochem., 2014, vol. 18, pp. 1389-1399. 


\title{
Synthesis of Novel Nanostructured Composite Cathode Materials for Lithium-Ion Batteries Using Mechanical Activation
}

\author{
N.V. Kosova and E.T. Devyatkina
}

\begin{abstract}
The principles of the application of mechanical activation for the synthesis of nanostructured composite cathode materials for lithium-ion batteries are proposed. The asprepared composite materials consist of two electrochemically active components and allow one to use the advantages of both of them. The results on the $\mathrm{LiCoO}_{2} / \mathrm{LiMn}_{2} \mathrm{O}_{4}$, $\mathrm{LiFePO}_{4} / \mathrm{Li}_{3} \mathrm{~V}_{2}\left(\mathrm{PO}_{4}\right)_{3}$ and $\mathrm{LiVPO}_{4} \mathrm{~F} / \mathrm{Li}_{3} \mathrm{~V}_{2}\left(\mathrm{PO}_{4}\right)_{3}$ composites are shown as an example. The proposed method offers the challenge to the development of novel electrode materials with enhanced electrochemical characteristics.
\end{abstract}




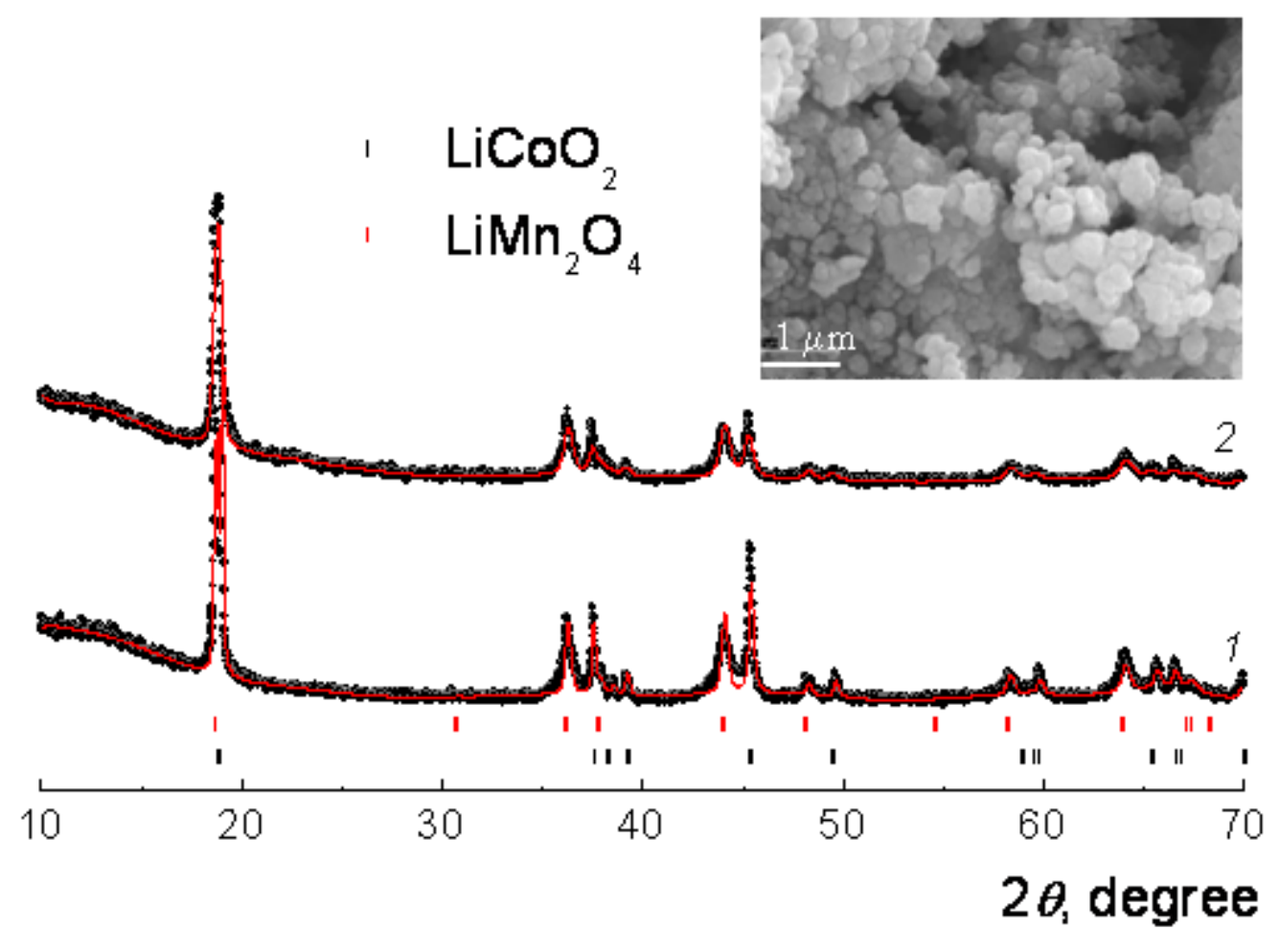

Fig. 1. 


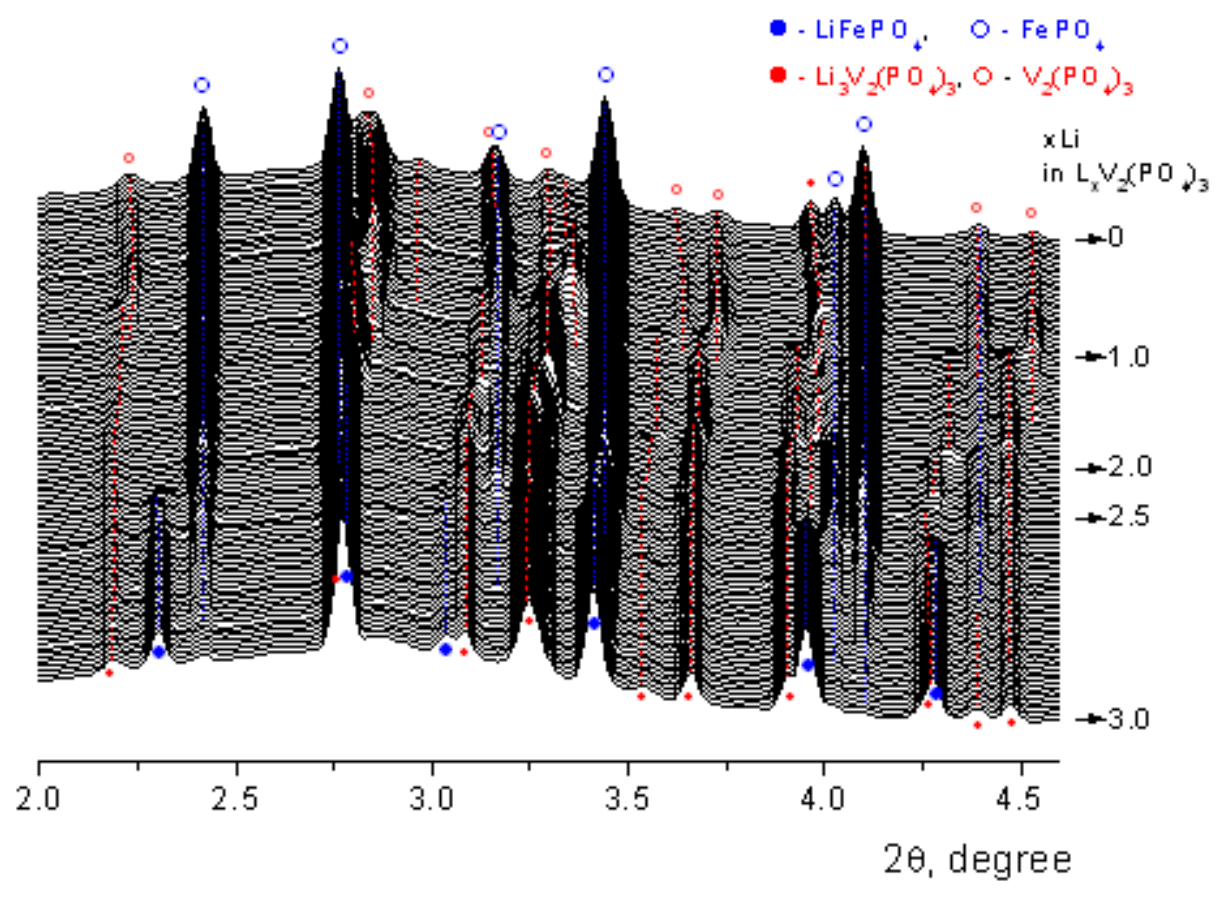

Fig. 2. 


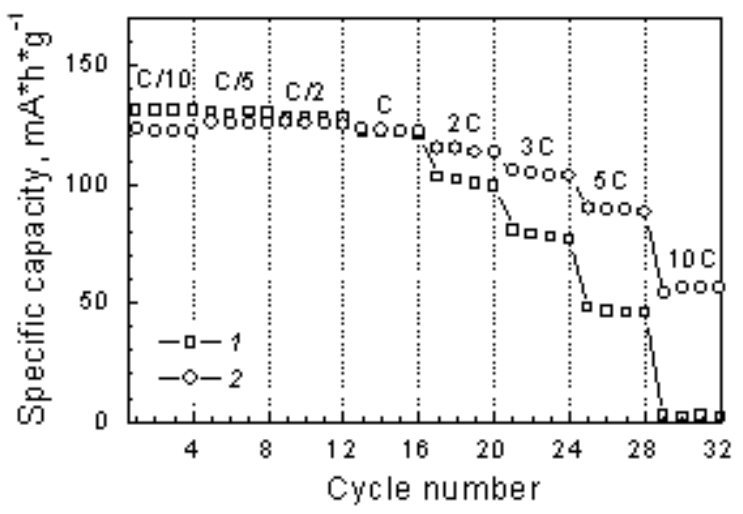

Fig. 3. 